\title{
GBP6: differential expression in pulmonary alveolar macrophages under PRRSV infection and association with blood parameters of its missense mutation
}

\author{
A.A. Adeyinka ${ }^{1,2,3}$, L. Niu ${ }^{1,2}$, C. Fang ${ }^{1,2}$, B. Babatunde ${ }^{4} \&$ X. Xu $\mathbf{X}^{1,2 \#}$ \\ ${ }^{1}$ Key Laboratory of Agricultural Animal Genetics, Breeding and Reproduction, Ministry of Education \& College of Animal \\ Science and Technology, Huazhong Agricultural University, Wuhan 430070, China \\ ${ }^{2}$ The Cooperative Innovation Center for Sustainable Pig Production, Wuhan 430070, China \\ ${ }^{3}$ The Federal University of Technology Akure, P.M.B 704 Ondo State, Nigeria \\ ${ }^{4}$ Department of Chemical Sciences, Ondo State University of Science and Technology, Okitipupa, Nigeria
}

(Received 4 October 2016; Accepted 15 March 2017; First published online 14 August 2017)

Copyright resides with the authors in terms of the Creative Commons Attribution 4.0 South African Licence.
See: http://creativecommons.org/licenses/by/4.0/za
Condition of use: The user may copy, distribute, transmit and adapt the work, but must recognise the authors and the South African
Journal of Animal Science.

\begin{abstract}
The GBP6 gene belongs to the gene family of interferon-gamma inducible GTPases, and is located in a previously characterized QTL region of porcine reproductive and respiratory syndrome virus (PRRSV) resistance in SSC4. In the current study, RT-PCR assay revealed that the GBP6 gene was widely distributed but highly expressed in spleen and lung. Under PRRSV infection, the GBP6 gene was up-regulated and differentially expressed in the pulmonary alveolar macrophages (PAMs) of Large White and Tongcheng pigs. Multiple sequences alignment and phylogenetic analysis revealed that GBP6 is highly conserved across species. We validated and analyzed the polymorphism of a missense mutation (n.932A $>\mathrm{G}$, rs322187731) in the F2 resource population of Duroc $\times$ Erhualian, which changed the Valine (V) to Methionine $(\mathrm{M})$ in the 300th residue of porcine GBP6. Through a linear mixed effects model, the polymorphism of the mutation (n.932A $>$ G, rs322187731) was significantly associated with five haematological traits, namely platelet count at 20 days (PLT-20), plateletcrit at 20 days (PCT-20), white blood cell at 33 days (WBC-33), neutrophil count at 33 days (NE-33) and red blood cell count at 80 days (RBC-80). The findings presented here provide basic information for the function and possible involvement of the GBP6 gene in immune regulation and disease resistance.
\end{abstract}

Keywords: Association analysis, GBP6, haematological traits, pig, PRRSV

\# Corresponding Author: xuewen_xu@mail.hzau.edu.cn

\section{Introduction}

Porcine reproductive and respiratory syndrome (PRRS), the most global viral syndrome in the pig industry, is caused by a single-strand positive RNA virus, which was first isolated and classified as an arterivirus in 1991, and was called 'mystery swine disease' (Elazhary et al., 1991, Wensvoort et al., 1991, Goyal, 1993). It was also tagged as blue-ear disease in China (Tian et al., 2007, Tong et al., 2007). Porcine respiratory and reproductive syndrome virus (PRRSV) affects all stages of pig production (Zhang et al., 2016). In grower pigs, it limits the work of general defence mechanisms and predisposes the animals to common diseases such as pneumonia (Goyal, 1993, Schweer et al., 2016). PRRSV has a preference in pulmonary alveolar macrophages (PAM), where it replicates extensively (Bautista et al., 1993, Lee et al., 2010). The recognition and controlling of PRRSV infection is crucial to limit the adverse effects on pig production and economic losses to a minimum. So far, vaccination alone seldom provides satisfactory results for the farmer (Kimman et al., 2009, Chae, 2016). Multiple artificial infection experiments with PRRSV on different pig breeds revealed that host genetic background has big influence on the disease resistance or tolerance, indicating the possibility of genetic improvement of host resistance against PRRSV infection (AitAli et al., 2007, Lewis et al., 2007, Rowland et al., 2012).

To reveal the genetic basis of the host response to PRRSV infection, the PRRS Host Genetics Consortium (PHGC) was established and conducted artificial infection experiment in a commercial crossbred population (Lunney et al., 2011). Consequently, they identified an $1 \mathrm{Mb}$ region consisted of 33 consecutive SNPs on SSC4, which harbours a quantitative trait locus (QTL) related to PRRSV resistance or tolerance, and the favorable haplotype was associated with lower virus burden and increased weight gain (Boddicker et al., 2012, Boddicker et al., 2014). Five genes of the guanylate-binding protein (GBP) family, including GBP1, 
GBP2, GBP4, GBP5, and GBP6, were located within this QTL region. The guanylate-binding protein family was a family of interferon-gamma inducible GTPases, which play a crucial role in resistance to intracellular bacteria and protozoa (Vestal and Jeyaratnam, 2011). Polymorphisms of GBP1 and GBP2 in pigs have been evaluated for association with immune capacity traits such as red blood cell count and haematological parameters (Ma et al., 2008). Recently, the allele specific expression of GBP1 was compared according to the genotype of the marker "WUR1000125" in its 3'UTR and revealed the association of the marker and differential allele expression (Gol et al., 2015). More recently, the polymorphism of "WUR1000125" in GBP1 was found to be associated with the average daily gain in PRRSV vaccinated pigs (Abella et al., 2016) and T cell activation under PRRSV infection (Niu et al., 2016). Meanwhile, an intronic SNP in GBP5, rs340943904, was regarded as a strong candidate causal mutation (Koltes et al., 2015). In general, research on overall expression patterns of GBP genes in pigs has shown evidence of their correlation with weight gain under PRRSV infection (Gol et al., 2015, Koltes et al., 2015), however, which member of this family is the causative gene remains an uncertainty.

Whole blood transcriptome analyses of swine responses to PRRSV infection ranked GBP6 gene as one of the top differentially expressed genes (Choi, 2014). In addition, our previous PRRSV analysis of differentially expressed genes in PAM cells revealed GBP6 was differentially expressed in both the Chinese indigenous Tongcheng and the Western Large White (Liang et al., 2017). Thus, in the present study, we further analyzed the expression of GBP6 in PAM cells of control and PRRSV infected pigs, and evaluated the effect of variant of GBP6 (n.932A>G, rs322187731) in the $F_{2}$ population of Duroc $\times$ Erhualian, which were treated with poly I:C.

\section{Materials and methods}

All research procedures and animal care activities were strictly conducted in accordance with the guidelines established for the care and use of laboratory animals of the Standing Committee of Hubei People's Congress (No. 5) and approved by the Animal Care Committee of Hubei Province, P.R. China, and the Ethics Committee of Huazhong Agricultural University, P. R. China.

The artificial infection experiment of PRRSV and its results were introduced in detail in our previous paper (Liang et al., 2016). Briefly, twenty-four five-week-old piglets were randomly selected: 12 from the Large White pig population and 12 from the Tongcheng pig population. Neither population had experienced PRRSV infection, according to the farm's records. To confirm the health status of all the experimental piglets, at four weeks old they were tested for PRRSV, porcine circovirus, and pseudorabies virus. The results proved to be negative. Next, when the animals had acclimatized to the new experimental conditions at exactly one week, they were divided equally into two experimental groups (the infected groups) and two control groups (the non-infected groups). The experimental groups and control groups were kept in two separate rooms that were designed for disease research work, where each piglet was kept in a separate pen and fed ad libitum. All piglets in the experimental groups received an intramuscular challenge on day 0 with PRRSV solution at a dose of $3 \mathrm{~mL}$ per $15 \mathrm{~kg}$. Animals in the control groups were challenged with RPMI-1640 at the same dose. All pigs were humanely euthanized for necropsy at seven days post challenge. Pigs' left lungs were collected, and phosphate buffer was used to lavage the broncho-alveolar tract. The filtration of broncho-alveolar lavage fluid was suspended with Trizol reagent (Invitrogen, Carlsbad, Calif, USA).

The total RNA from PAMs was extracted according to the manufacturer's protocol, and reverse transcription to cDNA was conducted using PrimeScript ${ }^{\mathrm{TM}} \mathrm{RT}$ reagent Kit (Takara) in accordance with the manufacturer's recommendations. The $25 \mu \mathrm{L}$ qRT-PCR reaction contained $12.5 \mu \mathrm{L} 2 \mathrm{x}$ SYBR qPCR mix (Aidlab Biotechnologies Co., Ltd China), $0.5 \mu \mathrm{L}(10 \mu \mathrm{M})$ of each primer, and $1 \mu \mathrm{L}$ diluted CDNA. PCR amplification was carried out in triplicate using Bio-Rad Laboratory Inc device at $95{ }^{\circ} \mathrm{C}$ for 2 minutes, followed by 45 cycles at $95^{\circ} \mathrm{C}$ for 10 seconds and $60^{\circ} \mathrm{C}$ for 15 seconds. The primers used in the present study were listed in Table 1 . The relative expression ratios of the GBP6 gene were calculated by the $2^{-\triangle \Delta C t}$ method (Livak and Schmittgen, 2001) using the pig housekeeping gene beta-actin as the endogenous reference gene. Data were subjected to statistical analysis using GraphPad Prism 5 software (Motulsky, 2007). $P<0.05$ was considered as the threshold of statistical significance. Owing to the qualitative study of GBP6 expression in tissues, $2 \mu \mathrm{g}$ total RNA from eight tissues including heart, liver, spleen, lung, kidney, longissimus dorsi, subcutaneous fat, and brain were digested with RNase-free DNase I (Cat „RRO47A China) to eliminate genomic DNA. The treated RNA was used for first-strand cDNA synthesis with PrimeScript ${ }^{\mathrm{TM}}{ }_{\mathrm{RT}}$ reagent Kit (Cat ${ }_{\# R R O 47 B)}$ in $20 \mu \mathrm{L}$ reactions, as indicated by the manufacturers. Semi-quantitative real-time PCR (32cycles) was employed to analyse tissue distribution using the gene-specific primers listed in Table 1. The beta-actin gene was used as an endogenous reference gene. 
Table 1 Primer pairs used for viability assay of GBP6 gene

\begin{tabular}{|c|c|c|c|}
\hline GBP6 Gene & Primer Sequences (5'- 3') & PCR Tm (0C) & Product size (bp \\
\hline Gbp6-MUT.1F & CTACTAGGCAGCTCTTGCAGG & 60 & $996 b p$ \\
\hline Gbp6-MUT.1R & GATGACACGCAGGAGTTCCAG & & \\
\hline Gbp6-RT-PCR.1F & ACGCTCAGAGATGGAATCACAGTC & 64 & 177bp \\
\hline Gbp6-RT-PCR.1R & CATCTGCTCGCTGTAGAGGTCG & & \\
\hline Gbp6-qRT-PCR.2F & ACGCTCAGAGATGGAATCACAGTC & 60 & 177bp \\
\hline Gbp6-qRT-PCR.2F & CATCTGCTCGCTGTAGAGGTCG & & \\
\hline Beta-actin1F & GGACTTCGAGCAGGAGATGG & 60 & 233bp \\
\hline Beta-actin1R & GCACCGTGTTGGCGTAGAGG & & \\
\hline PCR-RFLP 1F & GGCTTCTTCAGGGCTGGGGAC & 64 & 179bp \\
\hline PCR-RFLP 1R & CTGTGGGGAGGCTCAGTCGCT & & \\
\hline
\end{tabular}

To determine the presence of GBP6 genes in vertebrates, we used reciprocal Blast best hits to search candidate genes from NCBI databases (with identity $>40 \%$, overlap $>60 \%$, e-value $<1$ - 10 ). In addition, we consulted the GBP6 orthologues database in ENSEMBL. Sequence similarity was obtained with a BLAST program (http://www.ncbi.nlm.nih.gov/blast). The BLAST algorithm was used to search the http://www.ncbi.nlm.nih.gov/genome/ databases and ClustalW2 program to generate multiple sequence alignments (http://www.ebi.ac.uk/Tools/msa/clustalw2/). The homology for GBP6 transcript was inferred, and the evolutionary relationship between the transcripts of GBP6s from selected vertebrates was studied. A neighbour-joining tree was developed using MEGA 5.0 under the Poisson model, and bootstrap values were calculated from 2000 repetitions.

Missense mutation ( $\mathrm{n} .932 \mathrm{~A}>\mathrm{G}$, rs322187731) was identified based on porcine GBP6 Sscrofa10.2 primary assembly (GenBank accession no.NC_010445). PCRs were performed in a $25 \mu \mathrm{L}$ mix containing $50 \mathrm{ng}$ DNA, $2.5 \mu \mathrm{L}$ of $10 \times$ PCR buffer, $5 \mathrm{mM}$ of dNTPs, 10 pmol of forward and reverse primer, $0.625 \mathrm{U}$ Taq DNA polymerase (Takara Biotechnology Co. Ltd. China) and $\mathrm{ddH}_{2} \mathrm{O}$. The reaction conditions comprised an initial denaturation at $94^{\circ} \mathrm{C}$ for 5 minutes, followed by 34 cycles of $94{ }^{\circ} \mathrm{C}$ for 30 seconds, annealing at $60{ }^{\circ} \mathrm{C}$ for 40 seconds, $72{ }^{\circ} \mathrm{C}$ for 40 seconds, and a final extension at $72{ }^{\circ} \mathrm{C}$ for 10 minutes. The PCR products were sequenced directly with $A B I 3730 x I$ DNA analyser (Applied Biosystems) to confirm the mutation ( $n .932 A>G$, rs322187731). Then, PCR-RFLP assay was utilized for genotyping of the identified SNP (n.932A>G, rs322187731) in 306 individuals of Duroc $\times$ Erhualian F2 population (primers listed in Table 1). PCR-RFLP amplifications were carried out in a Bio-Rad T100 TM thermo-cycler (USA) in a total reaction volume of $20 \mu \mathrm{L}$ containing dNTP $(10 \mathrm{mM}) 0.2 \mu \mathrm{L}$, forward primer $(5 \mu \mathrm{M}) 0.2 \mu \mathrm{L}$, reverse Primer $(5 \mu \mathrm{M}) 0.2 \mu \mathrm{L}$, Taq polymerase $(2.5 \mathrm{U} / \mu \mathrm{l}) 0.4 \mu \mathrm{L}, 10 \mathrm{X}$ PCR buffer (20 mM MG2+) $2 \mu \mathrm{L}$, template DNA (25 ng/ $\mu \mathrm{l}) 2 \mu \mathrm{L}$, ddH2O 7.6 $\mu \mathrm{L}$. The PCR-RFLP condition for amplifying was pre-denaturing at $95{ }^{\circ} \mathrm{C}$ for 3 minutes, and 35 cycles of denaturation at $95^{\circ} \mathrm{C}$ for 30 seconds, annealing at $64^{\circ} \mathrm{C}$ for 30 seconds, extension at $72{ }^{\circ} \mathrm{C}$ for 20 seconds, and elongation at $72{ }^{\circ} \mathrm{C}$ for 7 minutes. The PCR-RFLP products were digested with an enzyme (Nla III) and electrophoresed using $3 \%$ agarose gel. The results of the PCR-RFLP were validated by i) PCR reactions run simultaneously with a negative control (a negative control contained the entire PCR component except for the DNA template); ii) $15 \%$ of all samples were repeated to confirm the results of PCR-RFLP.

Association analysis of GBP6 mutation ( $n .932 A>G$, rs322187731) was performed in an $F_{2}$ resource population. The population was established and managed as described by Liu et al. (2011). In brief, two phenotypic divergent pig breeds, Duroc and Erhualian, reciprocal crossed to generate $F_{2}$ population. These lines were chosen as potential candidates to breeding programs aiming at improving immune response. The population involved a total of 306 F2 individuals treated with poly I:C, an immuno-stimulant notably for inducing type I IFN response. Then, blood samples of $10 \mathrm{~mL}$ were collected immediately from the jugular veins of each animal after overnight fasting of at least 16 hours in four stages, namely days 20, 33, 35 and 80. Blood samples were injected directly into Eppendorf tubes containing $30 \mu \mathrm{L} 20 \%$ EDTA in polybutadienestyrene. A standard set of haematological data were recorded using an automated blood analyser (Abbott, USA). The 22 haematological parameters included 11 leukocyte traits, 6 erythrocyte traits, and 5 platelet traits. Genomic DNA was extracted from the tail, and ear tissues using TIANamp Genomic DNA Kit (TianGen, Beijing, China) according to the manufacturer's instructions, with minor modifications. A single-SNP marker analysis using linear mixed effects model approach was conducted to examine the association between the haematological traits in a total of 306 individuals. Each trait was corrected for fixed effects (i.e. sex, genotype, and environment). The association test was performed according to the following model: 


\section{$Y=X \beta+Z b+\varepsilon$}

Where: $Y$ is the response vector for observation traits

$X$ is the model matrix for the fixed effects for observations

$\beta$ is the $3 \times 1$ vector of fixed-effect coefficients (genotypes, sex, and environment)

$Z$ is the model matrix for the random effects for observations

$b$ is the $2 \times 1$ vector of random-effect coefficients (sire, dam)

$\varepsilon$ is the vector of errors for observations

The mean of $b$ and $\varepsilon$ are $0 . b$ should be thought of as being constant over subjects, while $\varepsilon$ should be thought of as independent between subjects. All statistical tests were implemented in R 3.1 (Pinheiro et al., 2014).

\section{Results}

Investigation of the general tissue distributions of GBP6 was performed by RT-PCR, using beta-actin as an internal control. GBP6 was expressed in all eight tissues, with the highest level in spleen and lung, whereas its expression in heart, liver, kidney, longissimus dorsi, subcutaneous fat, and brain were relatively weak (Figure 1A). We further detected its' expression in PAM cells by quantitative real-time PCR (qRT-PCR). As shown in Figure 1B, GBP6 was significantly up-regulated in PRRSV-infected PAM cells of both breeds, Large White and Tongcheng. The result showed a significant difference between infected and non-infected groups with average 8. 23-fold and average 1.09-fold in Large White and Tongcheng respectively.
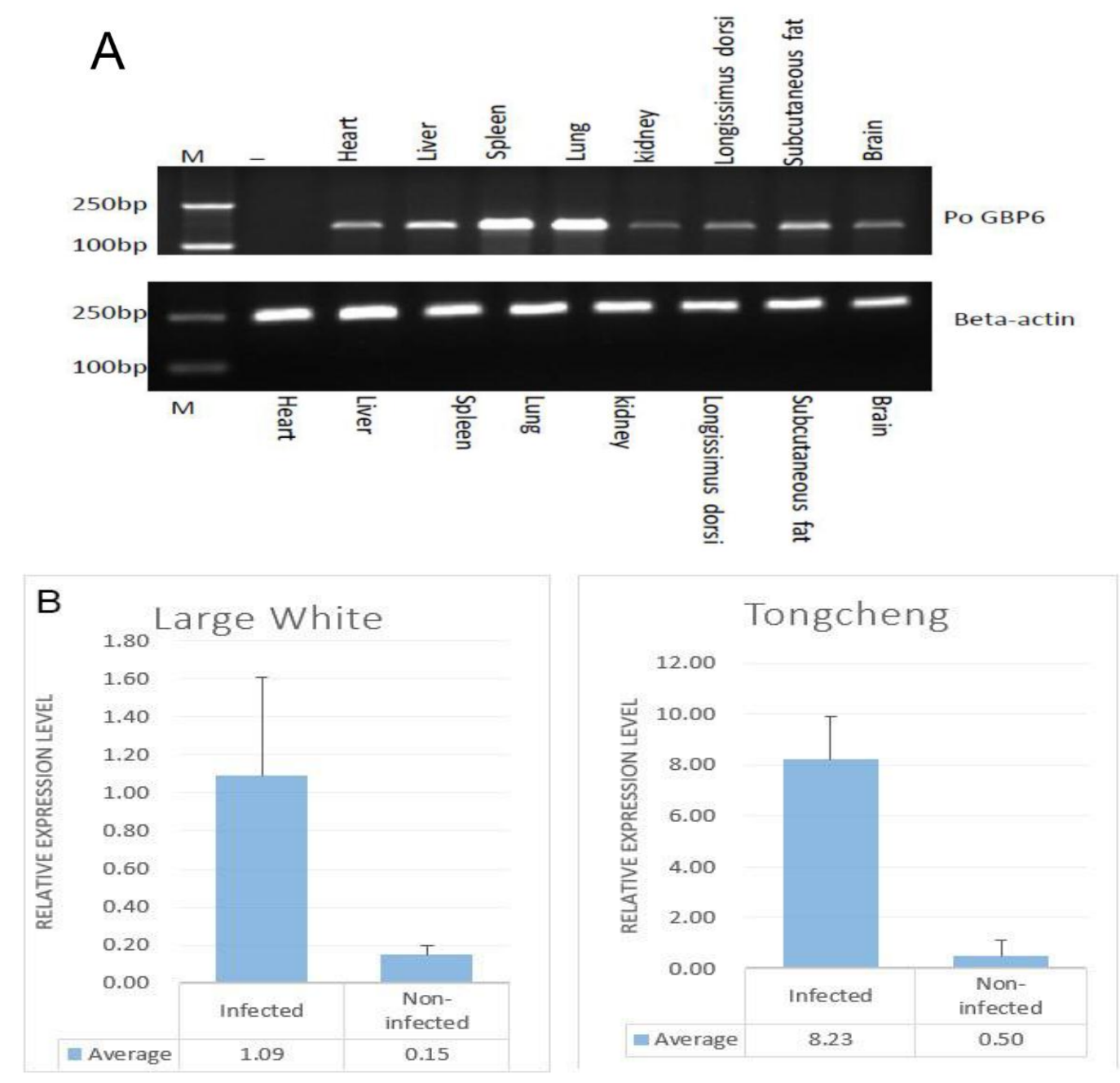

Figure 1 Expression trend of GBP6. (A) Tissue distribution analysis of GBP6. $\beta$-actin was amplified as the internal control. Lengths of the PCR products (GBP6: $177 \mathrm{bp} ; \beta$-actin: $233 \mathrm{bp}$ ) are marked in the figure; (-) (no cDNA) and M represent molecular weight $(\mathrm{MW})$ : 2000bp. (B) The significance difference $(P<0.05)$ between infected and non-infected 
groups for Large White and Tongcheng pigs. Error bars indicate standard deviations. Each bar represents the level of the target gene mRNA relative expression level.

Multiple transcript sequence alignment was generated using the CLUSTALW program with the default parameters. The bases with ambiguity were inspected manually and removed to optimize the alignment. Long stretches of identical amino acids indicated that GBP6 was highly conserved in vertebrates, especially for the R-loop containing nucleotide triphosphate hydrolase domain (IPR027417) in the N-terminal (7-280 residues for pig GBP6) (Figure 2). The percentage identities of pig GBP6 with other closely related vertebrates are cow (83.48\%), dog (80.32\%), human (82.35\%), mouse (82.35\%), gorilla (83.90\%), cat (83.60\%), guinea pig (87.25\%), dolphin (81.9\%), and elephant (91.64\%). The neighbour-joining tree revealed that pig GBP6 clustered with known GBP6s from cow, sheep, dolphin, dog, cat, gorilla, human, guinea pig, mouse, whereas elephant serves as an outgroup when determining the evolutionary relationship among the monophyletic groups of vertebrates used in this study (Figure 3).
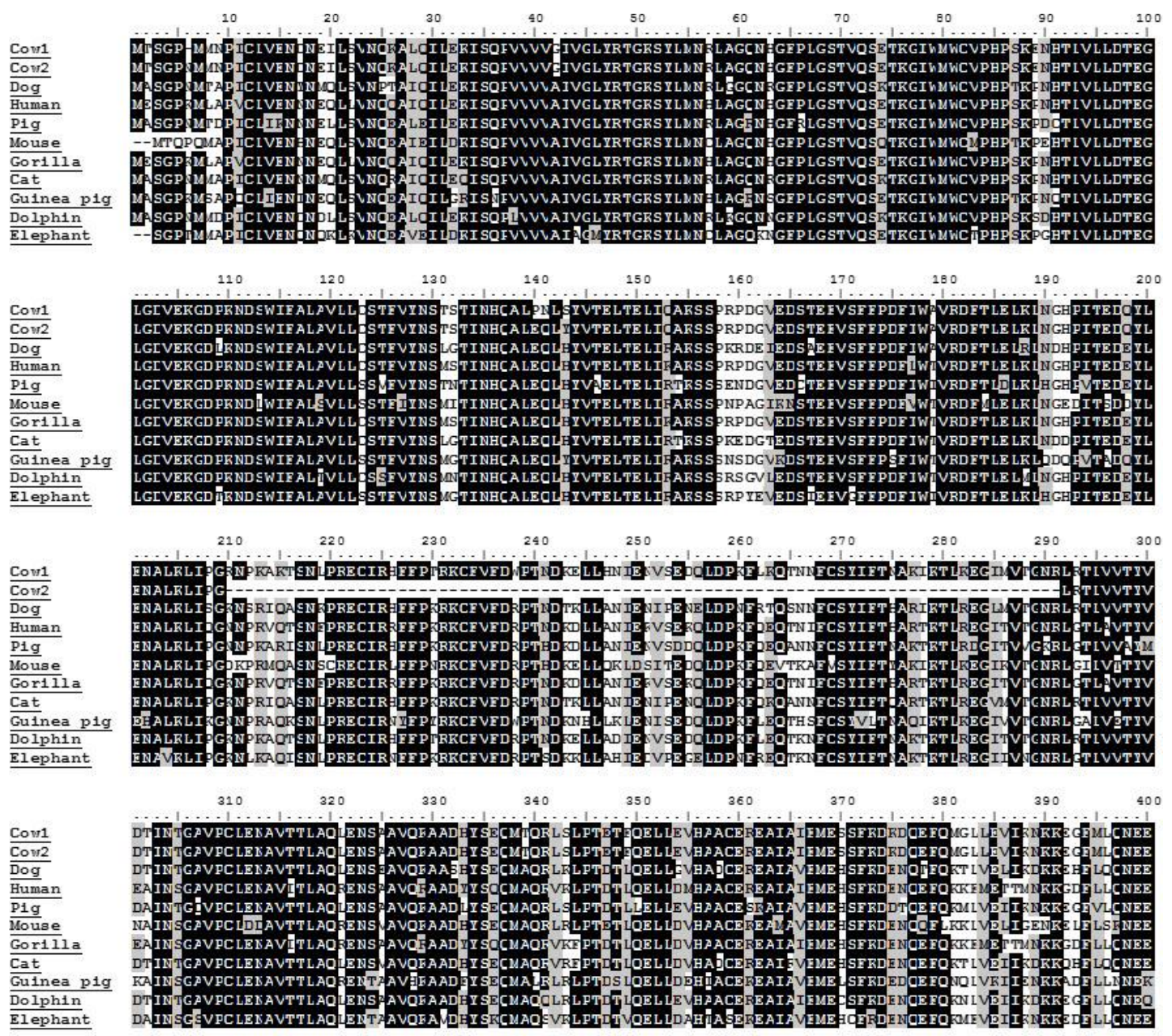

Figure 2 ClustalW multiple alignments of amino acid sequences of ten GBP6 in vertebrates. The alignment-layout was edited with the JalView Lite software. Identical and similar amino acid residues are indicated and shaded. The mutation (n.932A>G, rs322187731) are corresponding to the 300th residue. 


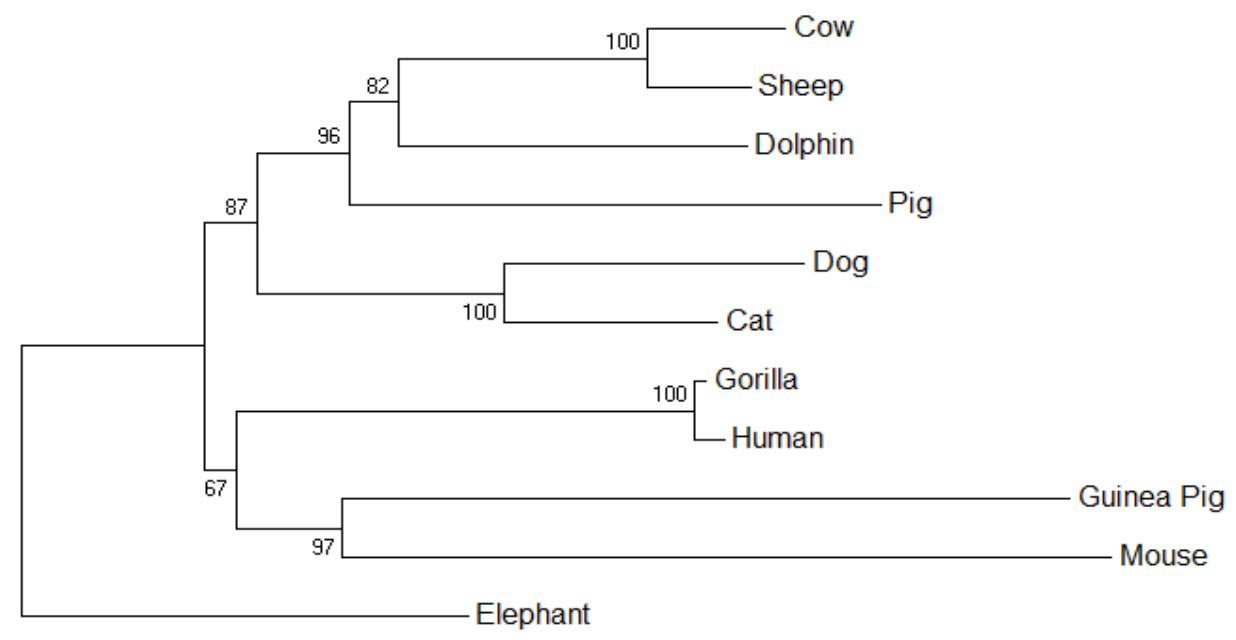

0.050

Figure 3 Phylogram representation of GBP6s from vertebrates. Numbers above branches show bootstrap support values. Branch lengths are shown proportionally to the amount of inferred evolutionary change.

SNP identified in the GBP6 gene (n.932 G>A, rs322187731) was detected through sequencing, the SNP was in exon 6 . The SNP was genotyped for subsequent association study in 306 F2 Duroc $\times$ Erhualian resource population. Their genotype and allele frequencies are presented in Table 2. Three genotypes, GG, AA (homozygotes) and heterozygote AG, conditioned by PCR-RFLP and detected by enzyme Nla/ll, resulting in allele $A(179 \mathrm{bp})$ and allele $G$ (139bp and 40bp) (Figure 4). Different genotypes of GBP6 were significantly associated with 5 haematological traits: PLT, PCT, WBC, NE, and RBC at 20, 20, 33, 33 and 80 days respectively (Table 2). Significant association between genotypes and traits were detected in both males and females for PCT-20, NE-33, and WBC-33, while the association between genotypes and PLT-20 was only found to be significant in females, and for RBC- 80 it was only detected in males.

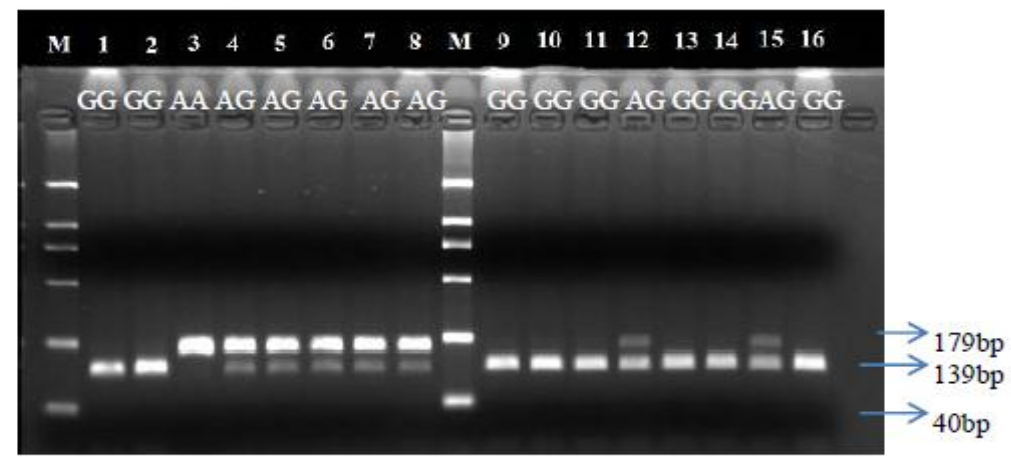

Figure 4 Polymorphic band pattern generated by PCR-RFLP analysis of GBP6. Lane 1-16, samples and molecular weight marker of $2000 \mathrm{bp}$

\section{Discussion}

GBP6 is an IFN-stimulated gene. In the present study, GBP6 was up-regulated upon PRRSV infection in both Tongcheng and Large white pigs. This is consistent with previous reported PRRSV artificial infection results, which showed that the expression of IFN-stimulated genes such as IFIT1, IFIT3, IFITM1, IFNb1, IRF1, JAK2, MX1 was up-regulated under PRRSV infection (Ait-Ali et al., 2008, Genini et al., 2008, Singleton et al., 2016). Meanwhile, interferon genes especially the interferon gamma gene (IFNG) are known to be strongly activated under PRRSV infection, which plays a vital role in the clearance of PRRSV virus (Badaoui et al., 2014, Zhou et al., 2011, Lunney et al., 2016). Thus, the interferon signaling pathway are activated during PRRSV infection, of which the Janus kinase and signal transducer activator of transcription pathway 
are key regulators controlling the transcription of the GBP6 gene (Darnell et al., 1994, Schindler and Darnell Jr, 1995, Stark et al., 1998).

Table 2 The implicated SNP and association analysis with haematological traits

\begin{tabular}{ccccccc}
\hline Traits & Number & Genotype & Mean \pm Std & $\begin{array}{c}\text { Estimated Effect } \pm \\
\text { Stde. }\end{array}$ & P-value & Sig. \\
\hline \multirow{2}{*}{ PLT20 } & 83 & AA & $684.78 \pm 154.82$ & $684.79 \pm 19.64$ & $6.65 \mathrm{E}-67$ & model \\
& 130 & AG & $600.96 \pm 106.98$ & $-83.83 \pm 26.52$ & 0.001964 & $* *$ \\
& 93 & GG & $580.94 \pm 118.02$ & $-103.84 \pm 28.69$ & 0.000425 & $* \star *$ \\
PCT20 & 83 & AA & $0.44 \pm 0.13$ & $0.44 \pm 0.02$ & $7.66 \mathrm{E}-55$ & model \\
& 130 & AG & $0.38 \pm 0.08$ & $-0.05 \pm 0.02$ & 0.007738 & $* *$ \\
& 93 & GG & $0.37 \pm 0.10$ & $-0.07 \pm 0.02$ & 0.00487 & $* *$ \\
WBC33 & 83 & AA & $23.73 \pm 8.44$ & $23.73 \pm 1.37$ & $1.12 \mathrm{E}-28$ & model \\
& 130 & AG & $17.90 \pm 6.41$ & $-5.83 \pm 1.76$ & 0.001371 & $* *$ \\
& 93 & GG & $18.41 \pm 4.65$ & $-5.32 \pm 2.00$ & 0.009524 & $*$ \\
NE33 & 83 & AA & $8.38 \pm 4.62$ & $8.38 \pm 0.85$ & $2.22 \mathrm{E}-15$ & model \\
& 130 & AG & $6.16 \pm 4.52$ & $-2.22 \pm 1.09$ & 0.045905 & $*$ \\
& 93 & GG & $5.45 \pm 2.72$ & $-2.93 \pm 1.25$ & 0.02114 & $*$ \\
RBC80 & 83 & AA & $6.66 \pm 1.21$ & $6.66 \pm 0.22$ & $4.11 \mathrm{E}-35$ & model \\
& 130 & AG & $7.29 \pm 0.79$ & $0.63 \pm 0.29$ & 0.035766 & $*$ \\
& 93 & GG & $7.31 \pm 0.66$ & $0.65 \pm 0.32$ & 0.043955 & $*$ \\
\hline
\end{tabular}

Single asterisk key $\left(^{*}\right)$ indicate significant differences between the various genotypes at $P<0.05$, and double asterisk key $\left({ }^{* \star}\right)$ indicate significant differences between the various genotypes at $P<0.01$ and three asterisk key $\left({ }^{\star \star}\right)$ indicate significant differences between the various genotypes at $P<0.001$.

Quantitative PCR analysis revealed that the GBP6 gene was expressed in all tissues that were examined. The highest expression was found in the spleen and lung. The spleen is the secondary lymphoid tissue in all vertebrates (Bar-Ephraim and Mebius, 2016), which means that the GBP6 protein probably expressed on the mature $B$ cells, which migrate from the spleen to blood and settle in secondary lymphoid tissues to assist in the immune response (LeBien and Tedder, 2008). PRRSV enters and replicates in macrophages and lymph nodes present in the lung (Xiao et al., 2010), suggesting that expression of GBP6 in the lung was important in the immune surveillance system in the organs of the pig (Beyer et al., 2000).

Multiple sequence alignment across several species as well as the phylogenetic analysis indicated that GBP6 is highly conserved among vertebrates. The mutation (n.932 G>A, rs322187731) that we analyzed in the current study caused the Valine $(\mathrm{V})$ changed to Methionine $(\mathrm{M})$ in the 300th residue. According to the multiple sequence alignment, this amino acid residue is highly conserved across species, therefore the missense mutation probably influences the protein function. Consistent with this point, the GBP6 missense mutation ( $\mathrm{n} .932 \mathrm{G}>\mathrm{A}$, rs322187731) had significant association with five haematological parameters, including PLT-20 $(P<0.01)$, PCT-20 $(P<0.01)$, WBC-33 $(P<0.01)$, NE-33 $(P<0.05)$, and RBC$80(P<0.05)$. The wild-type homozygous $(G G)$ displayed consistent lower value of PLT-20, PCT-20, WBC-33, $\mathrm{NE}-33$ than the homozygous of derived alleles (AA), indicating the AA homozygous individuals probably under more serious inflammation state under the stimulation of poly I:C.

\section{Conclusion}

The present study reveals that the GBP6 gene is up-regulated under PRRSV infection and differentially expressed in Large White and Tongcheng PAM cells. In addition, one missense mutation of GBP6 was proved to be associated with haematological traits in pigs under the stimulation of poly I:C. However, the relationship between the mutation genotypes and PRRSV resistance remains unknown, which need further investigation in PRRSV infection populations. 


\section{Acknowledgements}

The authors thank the research supporters, namely the Fundamental Research Funds for the central Universities (Program No. 2662015QC039).

\section{Authors' Contributions}

The experiment was conceived and designed by $X X$, and $A A A$. AAA, and NL carried out the experiment. Data analysis were performed by $\mathrm{XX}, \mathrm{CF}, \mathrm{AAA}$, and $\mathrm{BB}$. AAA, XX, and BB wrote the manuscript and all authors read and approved the final manuscript.

\section{Conflict of Interest Declaration}

The authors hereby declare no conflict of interest.

\section{References}

Abella, G., Pena, R. N., Nogareda, C., Armengol, R., Vidal, A., Moradell, L., Tarancon, V., Novell, E., Estany, J. \& Fraile, L., 2016. A WUR SNP is associated with European Porcine Reproductive and Respiratory Virus Syndrome resistance and growth performance in pigs. Res. Vet. Sci.104, 117-22.

Ait-Ali, T., Wilson, A., Westcott, D., Frossard, J., Mellencamp, M., Drew, T., Bishop, S. \& Archibald, A., 2008. Dynamic differential regulation of innate immune transcripts during the infection of alveolar macrophages by the porcine reproductive and respiratory syndrome virus. In: Animal Genomics for Animal Health (pp. 239-45. Karger Publishers.

Ait-ali, T., Wilson, A. D., Westcott, D. G., Clapperton, M., Waterfall, M., Mellencamp, M. A., Drew, T. W., Bishop, S. C. \& Archibald, A. L., 2007. Innate immune responses to replication of porcine reproductive and respiratory syndrome virus in isolated Swine alveolar macrophages. Viral Immunol. 20, 105-18.

Badaoui, B., Rutigliano, T., Anselmo, A., Vanhee, M., Nauwynck, H., Giuffra, E. \& Botti, S., 2014. RNA-sequence analysis of primary alveolar macrophages after in vitro infection with porcine reproductive and respiratory syndrome virus strains of differing virulence. PloS one. 9, e91918.

Bar-Ephraim, Y.E. \& Mebius, R.E., 2016. Innate lymphoid cells in secondary lymphoid organs. Immunol. Rev. 271, 18599.

Bautista. E.M., Goyal, S.M., Yoon, I.J., Joo, H.S. \& Collins, J.E., 1993. Comparison of porcine alveolar macrophages and CL 2621 for the detection of porcine reproductive and respiratory syndrome (PRRS) virus and anti-PRRS antibody. J. Vet. Diagn. Invest. 5, 163-5.

Beyer, J., Fichtner, D., Schirrmeir, H., Polster, U., Weiland, E., \& Wege, H. 2000. Porcine reproductive and respiratory syndrome virus (PRRSV): kinetics of infection in lymphatic organs and lung. Zoonoses Public Health. 47(1), 9-25.

Boddicker, N., Waide, E. H., Rowland, R. R., Lunney, J. K., Garrick, D. J., Reecy, J. M. \& Dekkers, J. C., 2012. Evidence for a major QTL associated with host response to porcine reproductive and respiratory syndrome virus challenge. J. Anim. Sci. 90, 1733-1746.

Boddicker, N. J., Garrick, D. J., Rowland, R. R., Lunney, J. K., Reecy, J. M. \& Dekkers, J. C., 2014. Validation and further characterization of a major quantitative trait locus associated with host response to experimental infection with porcine reproductive and respiratory syndrome virus. Anim. Genet. 45, 48-58.

Chae, C., 2016. Porcine respiratory disease complex: Interaction of vaccination and porcine circovirus type 2, porcine reproductive and respiratory syndrome virus, and Mycoplasma hyopneumoniae. Vet. J. 212, 1-6.

Choi, I., 2014. Whole Blood Transcriptome Analyses of Swine Responses to PRRSV infection. In: Plant and Animal Genome XXII Conference.

Darnell, J., Kerr, I. M. \& Stark, G. R., 1994. Jak-STAT pathways and transcriptional activation in response to IFNs and other extracellular signaling proteins. Science. 264, 1415-1421.

Elazhary, Y., Weber, J., Bikour, H., Morin, M. \& Girard, C., 1991. 'Mystery swine disease' in Canada. Vet Rec 129, 495-6.

Genini, S., Delputte, P.L., Malinverni, R., Cecere, M., Stella, A., Nauwynck, H.J. \& Giuffra, E., 2008. Genome-wide transcriptional response of primary alveolar macrophages following infection with porcine reproductive and respiratory syndrome virus. J. Gen. Virol. 89, 2550-2564.

Gol, S., Estany, J., Fraile, L. \& Pena, R., 2015a. Expression profiling of the GBP1 gene as a candidate gene for porcine reproductive and respiratory syndrome resistance. Anim. Genet. 46, 599-606.

Goyal, S.M., 1993a. Porcine reproductive and respiratory syndrome. J. Vet. Diagn. Invest. 5, 656-64.

Kimman, T.G., Cornelissen, L.A., Moormann, R.J., Rebel, J.M. \& Stockhofe-Zurwieden, N., 2009. Challenges for porcine reproductive and respiratory syndrome virus (PRRSV) vaccinology. Vaccine. 27, 3704-3718.

Koltes, J.E., Fritz-Waters, E., Eisley, C.J., Choi, I., Bao, H., Kommadath, A., Serão, N.V., Boddicker, N.J., Abrams, S.M. \& Schroyen, M., 2015. Identification of a putative quantitative trait nucleotide in guanylate binding protein 5 for host response to PRRS virus infection. BMC genomics. $16,1$.

LeBien, T.W. \& Tedder, T.F., 2008. B lymphocytes: how they develop and function. Blood. 112, 1570-1580.

Lee, Y.J., Park, C.K., Nam, E., Kim, S.H., Lee, O.S., Lee, D.S. \& Lee, C., 2010. Generation of a porcine alveolar macrophage cell line for the growth of porcine reproductive and respiratory syndrome virus. J. Virol. Methods. 163, 410-415.

Lewis, C. R., Ait-ali, T., Clapperton, M., Archibald, A. L. \& Bishop, S., 2007. Genetic perspectives on host responses to porcine reproductive and respiratory syndrome (PRRS). Viral Immunol. 20, 343-58.

Liang, W., JI, L., Zhang, Y., Zhen, Y., Zhang, Q., Xu, X. \& Liu, B., 2017. Transcriptome Differences in Porcine Alveolar Macrophages from Tongcheng and Large White Pigs in Response to Highly Pathogenic Porcine Reproductive and Respiratory Syndrome Virus (PRRSV) Infection. Int. J. Mol. Sci. 18, 1475. 
Liang, W., Li, Z., Wang, P., Fan, P., Zhang, Y., Zhang, Q., Wang, Y., Xu, X. \& Liu, B., 2016. Differences of immune responses between Tongcheng (Chinese local breed) and Large White pigs after artificial infection with highly pathogenic porcine reproductive and respiratory syndrome virus. Virus Res. 215, 84-93.

Liu, X.-D., Chen, H.B., Tong, Q., Li, X.Y., Zhu, M.J., Wu, Z.F., Zhou, R. \& Zhao, S.H., 2011. Molecular characterization of caveolin-1 in pigs infected with Haemophilus parasuis. J. Immunol. 186, 3031-3046.

Livak, K.J. \& Schmittgen, T.D., 2001. Analysis of relative gene expression data using real-time quantitative PCR and the 2- $\triangle \Delta$ CT method. Methods. 25, 402-8.

Lunney, J.K., Fang, Y., Ladinig, A., Chen, N., Li, Y., Rowland B. \& Renukaradhya G.J., 2016. Porcine reproductive and respiratory syndrome virus (PRRSV): pathogenesis and interaction with the immune system. Annu. Rev. Anim. Biosci. 4, 129-154.

Lunney, J. K., Steibel, J. P., Reecy, J. M., Fritz, E., Rothschild, M. F., Kerrigan, M., Trible, B. \& Rowland, R. R., 2011. Probing genetic control of swine responses to PRRSV infection: current progress of the PRRS host genetics consortium. BMC Proc. 5 Suppl 4, S30.

Ma, G., Huang, J., Sun, N., Liu, X., Zhu, M., Wu, Z. \& Zhao, S., 2008. Molecular characterization of the porcine GBP1 and GBP2 genes. Mol. Immunol. 45, 2797-807.

Motulsky, H., 2007. In GraphPad Prism 5: Statistics Guide. GraphPad Software Inc. Press, San Diego CA, 94.

Niu, P., Shabir N., Khatun, A., Seo, B.J., Gu, S., Lee, S.M., Lim, S.K., Kim, K.S. \& Kim, W.I., 2016. Effect of polymorphisms in the GBP1, Mx1 and CD163 genes on host responses to PRRSV infection in pigs. Vet. Microbiol. 182, 187-95.

Pinheiro, J., Bates, D., DebRoy, S. \& Sarkar, D., 2014. R Core Team. nlme: linear and nonlinear mixed effects models. R package version 3.1-117. URL: http://cran. r-project. org/web/packages/nlme/index. html.

Rowland, R.R., Lunney, J. \& Dekkers, J., 2012. Control of porcine reproductive and respiratory syndrome (PRRS) through genetic improvements in disease resistance and tolerance. Front. Genet. 3, 260.

Schindler, C. \& Darnell, Jr J., 1995. Transcriptional responses to polypeptide ligands: the JAK-STAT pathway. Annu. Rev. Biochem. 64, 621-52.

Schweer, W., Schwartz, K., Burrough, E., Yoon, K., Sparks, J. \& Gabler, N., 2016. The effect of porcine reproductive and respiratory syndrome virus and porcine epidemic diarrhea virus challenge on growing pigs I: Growth performance and digestibility. J. Anim. Sci. 94, 514-22.

Singleton, H., Bodman-Smith, K., Frossard, J. \& Steinbach, F., 2016. Establishing porcine monocyte-derived macrophage and dendritic cell systems for studying the interaction with PRRSV-1. Front. Microbiol. 7.

Stark, G.R., Kerr, I.M., Williams, B.R., Silverman, R.H. \& Schreiber, R.D., 1998. How cells respond to interferons. Annu. Rev. Biochem. 67, 227-264.

Tian, K., Yu, X., Zhao, T., Feng, Y., Cao, Z., Wang, C., Hu, Y., Chen, X., Hu, D. \& Tian, X., 2007. Emergence of fatal PRRSV variants: unparalleled outbreaks of atypical PRRS in China and molecular dissection of the unique hallmark. PloS one. 2, e526.

Tong, G.Z., Zhou, Y.J., Hao, X.F., Tian, Z.J., An, T.Q. \& Qiu, H.J., 2007. Highly pathogenic porcine reproductive and respiratory syndrome, China. Emerg. Infect. Dis. 13, 1434-6.

Vestal, D.J. \& Jeyaratnam,J.A., 2011. The guanylate-binding proteins: emerging insights into the biochemical properties and functions of this family of large interferon-induced guanosine triphosphatase. J. Interferon Cytokine Res. 31, 89-97.

Wensvoort, G., Terpstra, C., Pol, J., Ter Laak, E., Bloemraad, M., De Kluyver, E., Kragten, C., Van Buiten, L.d., Den Besten, A. \& Wagenaar, F., 1991. Mystery swine disease in The Netherlands: the isolation of Lelystad virus. Vet. Q. 13, 121-30.

Xiao, S.Q., Jia, J.Y., Mo, D.L., Wang, Q.W., Qin, L.M., He, Z.Y., Zhao, X.A., Huang, Y.K., Li, A.N., Yu, J.W., Niu, Y.N., Liu, X.H. \& Chen, Y.S., 2010. Understanding PRRSV Infection in Porcine Lung Based on Genome-Wide Transcriptome Response Identified by Deep Sequencing. PloS one. 5.

Zhang, Q., Xu, X., You, S., Li, Y., Wang, H., Bai, J. \& Jiang, P., 2016. Emerging of two new subgenotypes of porcine reproductive and respiratory syndrome viruses in Southeast China. Microbial pathogenesis. 97, 27-33.

Zhou, P., Zhai, S., Zhou, X., Lin, P., Jiang, T., Hu, X., Jiang, Y., Wu, B., Zhang, Q. \& Xu, X., 2011. Molecular characterization of transcriptome-wide interactions between highly pathogenic porcine reproductive and respiratory syndrome virus and porcine alveolar macrophages in vivo. Int. J. Biol. Sci. 7, 947-59. 